\title{
miR-211 regulates the expression of $R R M 2$ in tumoral metastasis and recurrence in colorectal cancer patients with a $k$-ras gene mutation
}

\author{
CHIU-CHUN CHANG ${ }^{1,2^{*}}$, CHUN-CHE LIN $^{1-3^{*}}$, CHIA-HUNG WANG ${ }^{4}, \mathrm{CHI}_{-\mathrm{CHOU} \text { HUANG }^{3,5} \text {, TAO-WEI KE }}^{6}$, \\ PO-LI WEI ${ }^{7-10}$, KEN-TU YEH ${ }^{11}$, KAI-CHENG HSU ${ }^{9,10}$, NAN-YUNG HSU ${ }^{9,10,12,13}$ and YA-WEN CHENG ${ }^{9,10,14,15}$ \\ ${ }^{1}$ Institute of Medicine, College of Medicine, Chung Shan Medical University; ${ }^{2}$ Department of Internal Medicine, \\ Division of Gastroenterology, Chung Shan Medical University Hospital; ${ }^{3}$ School of Medicine, College of Medicine,

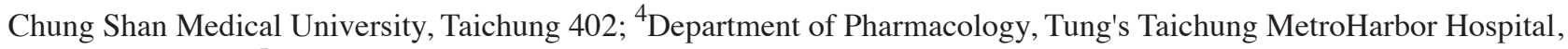 \\ Taichung $435 ;{ }^{5}$ Department of Surgery, Division of General Surgery, Chung Shan Medical University Hospital; \\ ${ }^{6}$ Department of Surgery, Division of General Surgery, China Medical University Hospital, Taichung 402; \\ ${ }^{7}$ Department of Surgery, Division of General Surgery, Taipei Medical University Hospital; ${ }^{8}$ School of Medicine, \\ Taipei Medical University; ${ }^{9}$ Cancer Center, Taipei Medical University Hospital, Taipei Medical University; \\ ${ }^{10}$ Graduate Institute of Cancer Biology and Drug Discovery, College of Medical Science and Technology, \\ Taipei Medical University, Taipei 115; ${ }^{11}$ Department of Pathology, Changhua Christian Hospital, Changhua 500; \\ ${ }^{12}$ Department of Surgery, Taipei Medical University Hospital, Taipei 100, Taiwan, R.O.C.; ${ }^{13}$ Division of Thoracic Surgery, \\ Ningbo Medical Center Lihuili Eastern Hospital, Ningbo, Zhejiang 315040, P.R. China; ${ }^{14}$ Translational Cancer Research \\ Center, Taipei Medical University; ${ }^{15}$ Department of R\&D, Calgent Biotechnology Co., Ltd, Taipei 100, Taiwan, R.O.C.
}

Received May 22, 2017; Accepted February 2, 2018

DOI: $10.3892 / \mathrm{ol} .2018 .8295$

\begin{abstract}
Colorectal cancer (CRC) ranks as the third-leading cause of cancer-associated mortalities in Taiwan. The expression of ribonucleotide reductase $\mathrm{M} 2$ (RRM2) and p53R2 is associated with tumoral malignancy and progression in several types of cancer. The aim of the present study was to determine the association of $p 53 R 2 / R R M 2$ with the upstream expression of microRNA ( $m i R)-211$ and the association of expression levels of $p 53, A P C$ and $k$-ras with clinical outcomes in patients with CRC. The study consisted of 192 tumor tissue samples obtained from patients with CRC. Immunohistochemistry and direct sequencing of DNA were performed to analyze p53R2/RRM 2 protein expression and p53/APC/k-ras gene mutations in these samples. The expression level of $m i R-211$ was detected by reverse transcription-quantitative polymerase chain reaction. The results showed that the expression of
\end{abstract}

Correspondence to: Professor Ya-Wen Cheng, Graduate Institute of Cancer Biology and Drug Discovery, College of Medical Science and Technology, Taipei Medical University, 3 Bade Road, Nangang, Taipei 115, Taiwan, R.O.C.

E-mail: ywc@tmu.edu.tw

${ }^{*}$ Contributed equally

Key words: ribonucleotide reductase M2, miRNA-211, metastasis, colorectal cancer
p53R2 was lower and that of $R R M 2$ was higher in patients with lymph node metastasis, distant metastasis, and late-stage CRC compared with patients without lymph node metastasis, distant metastasis and early-stage CRC. A high expression of $R R M 2$ in patients had a negative effect on overall survival (OS) and disease-free survival (DFS) in CRC. Positive expression of $R R M 2$ was detected in tumor tissues, and expression associated with the presence of $k$-ras gene mutation. Furthermore, it was detected that the upstream $m i R-211$ expression was negatively associated with $R R M 2$ expression in tumor tissues of patients with CRC. $m i R-211$ expression was associated with survival and tumoral recurrence in patients with $k$-ras mutations. The present authors suggest that the downregulation of $m i R-211$ and overexpression of RRM2 in tumor tissues of patients with CRC could be used to predict metastases and disease prognosis, particularly in patients with $k$-ras gene mutations.

\section{Introduction}

Colorectal cancer (CRC) ranks as the third-leading cause of cancer-associated mortalities in Taiwan (1). The majority of Taiwanese patients with CRC (60-70\%) present with stage II-IV disease at initial diagnosis $(2,3)$. Among newly diagnosed cases, $\sim 20-25 \%$ of patients have advanced disease with distant metastases $(2,3)$. Recurrence occurs in $~ 30 \%$ of patients with advanced CRC, even following curative resection (2). Patients with stage I and II CRC have an 86-95\% five-year survival rate, whereas those with stage III and IV metastatic diseases have five-year survival rates of $\sim 67$ and $\sim 12 \%$, respectively (3). In a previous study by the present authors, it was reported that 
the genetic background of Taiwanese patients with CRC was different from that of Caucasian patients with CRC (4). In the study, $\sim 33.8 \%$ of tumor tissues in Taiwanese patients with CRC contained Adenomatous polyposis coli (APC) mutations. This figure is close to that reported in Asia but significantly lower compared with the values reported in western countries (70-80\%) (5). Therefore, studies of the dynamic nature of molecular signatures in $\mathrm{CRC}$ are required to determine the prognosis of patients.

Ribonucleotide reductase ( $R R$ ) is a highly regulated rate-limiting enzyme that is used in the conversion of ribonucleoside diphosphate to 2'-deoxyribonucleoside diphosphate (6), and it is essential for DNA synthesis $(6,7)$. In humans, one large subunit (M1) and two small subunits (RRM2 and p53R2) of RR have been identified (6,7). Although the protein sequence of the two small RR subunits, p53R2 and RRM2, show $80 \%$ similarity, their biological function is markedly different (7). Previous reports demonstrated that the regulation of $R R M 2$ and $p 53 R 2$ might play a critical role in the invasion potential of cancer cells and the establishment of the metastatic phenotype $(8,9)$. Research also suggested that RRM2 might potentially serve as a biomarker for predicting aggressive $\mathrm{CRC}$, with poor survivability and progression-free survival (10). Inhibition of $R R$ activity has been tested as a potential therapy in anticancer settings (11). Therefore, the overexpression of $R R M 2$ has an important role in the pathogenesis of CRC.

Research has suggested that microRNAs (miRNAs), which are small, noncoding RNAs, modulate gene expression by degrading mRNA and/or inhibiting protein translation (12). The dysregulation of miRNA has been implicated in numerous processes during tumoral progression (12). In previous reports by the present authors, it was demonstrated that different miRNAs were involved in the pathogenesis in CRC, depending on the presence or absence of an APC gene mutation (5,13-15). For example, miR-224 suppressed the migration of CRC cells by targeting cell division cycle 42 in patients with $C R C$ and an $A P C$ gene mutation (13). It was also demonstrated by the present authors that the downregulation of let-7a-5p in sera and tumor tissues of patients with CRC could be used to predict lymph node metastasis and disease prognosis (14). In addition, the present authors demonstrated that let-7a appeared to regulate the expression of miR-21 (15). miR-21 has oncogene-like activity and is highly expressed in several types of cancer (16). In a recent study, it was also found that patients with $A P C$ mutations and high miR-21 expression had lower APC gene expression and exhibited poorer overall survival (OS) rates compared with patients with $A P C$ mutations and low $m i R-21$ expression, $A P C$ wild-type and high $m i R-21$ expression, and $A P C$ wild-type and high $m i R-21$ expression (5). The same study demonstrated that the downregulation of $A P C$ gene expression was associated not only with expression of the $A P C$ gene mutation but also with upregulation of $m i R-21$ (5). Based on these findings, the present authors speculated that the expression of the $p 53, A P C$ and $k$-ras genes may be associated with miRNA expression in patients with CRC.

The $k$-ras gene is a member of the ras gene family (H-, $\mathrm{K}$ - and N-ras) (17). Oncogenic $k$-ras mutations have been detected in several types of cancer (e.g., lung, colon and pancreatic) (17). Additionally, $20-50 \%$ of primary colorectal tumors contain oncogenic $k$-ras mutations (18). Recent clinical trials verified that the $k$-ras gene mutation was associated with cetuximab resistance in patients with metastatic CRC (19). However, whether mutant $k$-ras genes affect survival rates, tumoral recurrence and drug resistance in patients with CRC and who receive adjuvant chemotherapy is unclear. Previous research identified a positive association between $R R M 2$ and $k$-ras genes, showing that re-expressed $k$-ras genes in a HKe3 colon cancer cell line induced RRM2 expression (20). Based on these findings, we suggest that the interaction of $k$-ras with $R R M 2$ may play a role in survival rates and drug resistance in CRC patients.

In the present study, it was hypothesized that the downregulation of $m i R-211$ would induce $R R M 2$ expression and promote tumorigenesis in CRC and that the expression levels of $m i R-211, p 53 R 2$ and RRM2 may be used as biomarkers to predict clinical outcomes and tumoral recurrence in CRC. It was also hypothesized that $p 53 / A P C / k$-ras gene mutations would result in overexpression of $R R M 2$ and have a role in disease progression and clinical outcomes of patients with CRC. Therefore, the associations between $m i R-211, p 53 R 2$ and $R R M 2$ gene expression and clinical outcomes in CRC patients with and without $p 53 / A P C / k$-ras mutations were analyzed.

\section{Patients and methods}

Study population. CRC tumor tissue samples were collected from 192 non-selected patients who underwent surgical resection for CRC at the Department of Surgery, Taipei Medical University Hospital (Taipei, Taiwan) between December 2011 and December 2013 (14). The acquisition of the samples and their subsequent examination were approved by the Institutional Review Board of Taipei Medical University (Taipei, Taiwan). Informed written consent was obtained from all the patients and/or guardians prior to the use of the resected specimens.

None of the participants had a previous history of cancer. The clinical stages and pathological features of primary tumors were defined according to the criteria of the American Joint Commission on Cancer (https://cancerstaging.org/referencestools/Pages/What-is-Cancer-Staging.aspx). A total of 33 of the 192 patients with stage IV disease and distant metastasis were enrolled in the present study, of which 5 had lung metastasis, 16 had liver metastasis, 9 had peritoneum metastasis and 3 had para-aortic lymph nodes metastasis. All of the patients had oligometastatic disease and had undergone surgery but not chemotherapy. Postoperative follow-up visits were scheduled every three months thereafter during the first two years, then every six months thereafter, or more frequently if needed. Survival and recurrence were followed up in all the patients in the present study.

The CRC tissues and paired non-tumor tissues from the aforementioned patients were obtained from the Tissue Bank of Taipei Medical University (Taipei. Taiwan) between December 2011 and December 2013. In the present study, a total 192 patients were enrolled, including 90 females and 102 males, age ranging from 40 to 90 years old. A pathologist confirmed that $>95 \%$ of the cells were tumor cells based on $\mathrm{H} \& \mathrm{E}$-stained frozen sections. The normal tissues were used as a control. These tissue samples were obtained from the same patient and were checked by a pathologist. 
Table I. Association of $p 53 R 2$ and $R R M 2$ expression and clinical parameters in tumor tissues of patients with colorectal cancer.

\begin{tabular}{|c|c|c|}
\hline \multicolumn{3}{|c|}{$\mathrm{A}, p 53 R 2$ expression } \\
\hline Parameters & Low $(\mathrm{n}=99)$ & $\operatorname{High}(n=93)$ \\
\hline \multicolumn{3}{|l|}{ Age, years } \\
\hline$\leq 65$ & 44 & 50 \\
\hline$>65$ & 55 & 43 \\
\hline P-value & 0.248 & \\
\hline \multicolumn{3}{|l|}{ Sex } \\
\hline Female & 43 & 47 \\
\hline Male & 56 & 46 \\
\hline P-value & 0.386 & \\
\hline \multicolumn{3}{|l|}{$\mathrm{T}$ factor } \\
\hline 1 & 5 & 2 \\
\hline 2 & 12 & 16 \\
\hline 3 & 57 & 53 \\
\hline 4 & 25 & 22 \\
\hline P-value & 0.562 & \\
\hline \multicolumn{3}{|l|}{$\mathrm{N}$ factor } \\
\hline 0 & 43 & 40 \\
\hline $1+2$ & 56 & 53 \\
\hline P-value & 1.000 & \\
\hline \multicolumn{3}{|l|}{$\mathrm{M}$ factor } \\
\hline 0 & 74 & 85 \\
\hline 1 & 25 & 8 \\
\hline P-value & 0.002 & \\
\hline \multicolumn{3}{|l|}{ Stage } \\
\hline I & 13 & 10 \\
\hline II & 24 & 29 \\
\hline III & 36 & 46 \\
\hline IV & 26 & 8 \\
\hline P-value & 0.008 & \\
\hline
\end{tabular}

$\mathrm{B}$, RRM2 expression

\begin{tabular}{lll}
\hline Parameters & Low $(\mathrm{n}=96)$ & High $(\mathrm{n}=96)$ \\
\hline
\end{tabular}

\begin{tabular}{lcr}
\hline Age, years & & \\
$\leq 65$ & 47 & 47 \\
$>65$ & 49 & 49 \\
P-value & 1.000 & \\
Sex & & 50 \\
Female & 40 & 46 \\
Male & 56 & \\
P-value & 0.193 & 3 \\
T factor & & 9 \\
1 & 4 & 59 \\
2 & 19 & 25 \\
3 & 51 & \\
4 & 22 & \\
P-value & 0.206 &
\end{tabular}

Table I. Continued.

$\mathrm{B}, R R M 2$ expression

\begin{tabular}{lcc}
\hline Parameters & Low $(\mathrm{n}=96)$ & High $(\mathrm{n}=96)$ \\
\hline N factor & & \\
0 & 53 & 66 \\
$1+2$ & 43 & \\
P-value & 0.001 & \\
M factor & & 77 \\
0 & 82 & 19 \\
1 & 14 & \\
P-value & 0.445 & 5 \\
Stage & & 20 \\
I & 18 & 52 \\
II & 33 & 19 \\
III & 30 & \\
IV & 15 & \\
P-value & 0.001 & \\
\hline
\end{tabular}

RRM2, ribonucleotide reductase M2; p53R2, ribonucleotide reductase regulatory TP53 inducible subunit M2B; T, tumor, M, metastasis; $\mathrm{N}$, node.

Reverse transcription-quantitative polymerase chain reaction $(R T-q P C R)$-based detection of miR-211. Total RNA was extracted from the tumor tissue samples or sera of the patients with CRC using TRIzol (Invitrogen; Thermo Fisher Scientific, Inc., Waltham, MA, USA). The expression of mature miRNA was detected by a TaqMan miRNA assay (Applied Biosystems, Thermo Fisher Scientific, Inc; catalog no. 4427975; sequence; UUCCCUUUGUCAUCCUUCGCCU) and normalized relative to U6B using the $2^{-\Delta \Delta \mathrm{Cq}}$ method (21). All TaqMan PCRs were performed in triplicate. The PCR reaction was conducted with the following conditions: starting with $95^{\circ} \mathrm{C}$ for $10 \mathrm{~min}$, followed by 40 cycles of amplification $\left(95^{\circ} \mathrm{C}\right.$ for $15 \mathrm{sec}$ and $60^{\circ} \mathrm{C}$ for $\left.1 \mathrm{~min}\right)$. The definition of high and low expression of $m i R-211$ was dependent on the mean value of the expression of these genes in the normal tissues of the patients. High expression was defined as expression levels higher than the mean expression in non-tumor tissues. Low expression was defined as expression levels lower than he mean expression in normal tissues. The mean expression level of $m i R-211$ in normal colon tissue samples was $20.21 \pm 10.81$. The PCR-based detection of $m i R-211$ was conducted as described in a previous report by the present authors (14).

Detection of p53R2 and RRM2 protein expression by immunohistochemistry. Formalin-fixed and paraffin-embedded specimens were sectioned at a thickness of $3 \mu \mathrm{m}$. All the sections were deparaffinized in xylene, sequentially rehydrated through serial dilutions of alcohol, and washed in phosphate-buffered saline. The sections used for $p 53 R 2$ and $R R M 2$ detection were immersed in a citrate buffer ( $\mathrm{pH}$ 6.0) and heated in a microwave oven twice for 5 min. Mouse anti-p53R2 (catalog no. SC-137174) and RRM2 

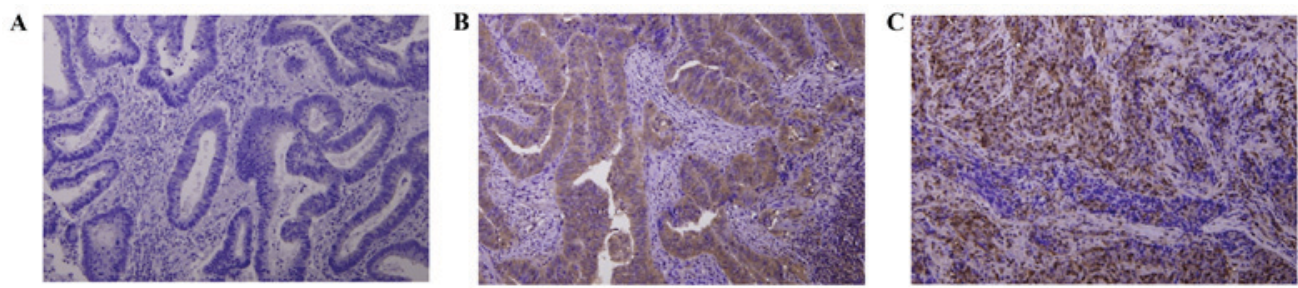

Figure 1. Immunohistochemical analysis of RRM2 and p53R2 proteins in colorectal cancer tissues. (A) Negative immunostaining (x200 magnification). Expression of (B) RRM2 (x200 magnification) and (C) p53R2 proteins (x400 magnification) in tumors. p53R2, ribonucleotide reductase regulatory TP53 inducible subunit M2B; RRM2, ribonucleotide reductase regulatory subunit M2.
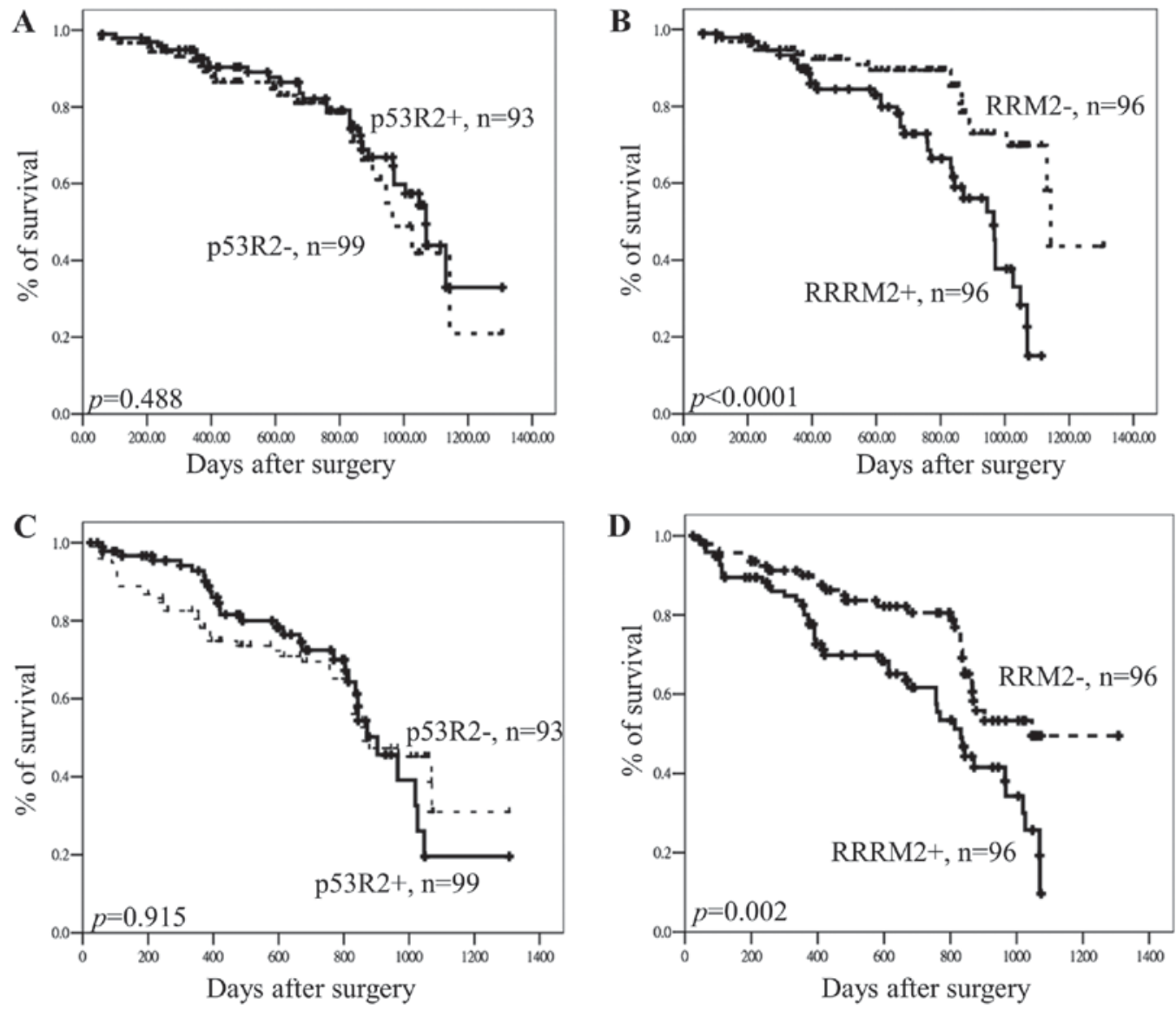

Figure 2. Overall survival curves of all patients with (A) p53R2 and (B) RRM2 expression. Disease-free survival curves of all patients with (C) p53R2 and (D) RRM2 expression. p53R2, ribonucleotide reductase regulatory TP53 inducible subunit M2B; RRM2, ribonucleotide reductase regulatory subunit M2.

(catalog no. SC-81850) monoclonal antibodies (all 1:100; Santa Cruz Biotechnology, Inc., Dallas, TX, USA) were used as the primary antibodies. The conventional streptavidin peroxidase method (DAKO; Agilent Technologies, Inc., Santa Clara, CA, USA; LSAB Kit K675) was performed to develop signals according to the manufacturer's protocol and the cells were counter-stained with hematoxylin. The details of the protocol used have been described previously (22). Negative controls that did not include the primary antibodies were also prepared.

A total of three observers independently evaluated the results and scored the percentage of positive expression in the samples. In each specimen, the cells that positively stained for anti-p53R2 and RRM2 antibodies were recorded as a percentage (\%) using a labeling index, and the measurements were calculated. The scores were as follows: 0 , no positive staining; + , from 1 to $10 \%$ positive cells; ++ , from 11 to $50 \%$ positive cells; and,$+++>50 \%$ positive cells. Among the 192 CRC patients, 99 samples were negative for $\mathrm{p} 53 \mathrm{R} 2$ protein expression. None of the patients were scored,+ 57 were scored ++ and 36 were scored +++. For RRM2 protein expression, 96 patients were negative. None of the patients were scored + , 35 were scored ++ and 61 were +++ . The scores of ++ and +++ were considered to represent high immunostaining, and scores of 0 and + were classified as low immunostaining.

Mutation analysis of APC, $k$-ras and p53 genes. Genomic DNA was prepared from 192 frozen CRC tissues using standard proteinase $\mathrm{K}$ digestion and phenol/chloroform extraction following homogenization. Mutations in the APC, p53 and $k$-ras genes were determined by direct sequencing of PCR 
products. The detailed protocol used has been described previously (23). The target sequences were amplified in a $50 \mu \mathrm{l}$ reaction mixture containing $20 \mathrm{pmol}$ of each primer, $2.5 \mathrm{U}$ Taq polymerase (Takara Bio, Inc., Otsu, Japan), $0.5 \mathrm{mmol} / 1$ dNTPs, $5 \mu \mathrm{l}$ PCR reaction buffer and $1 \mu \mathrm{l}$ genomic DNA as the template. Oligonucleotide primers were used to amplify the mutation cluster region of the $A P C, p 53$ and $k$-ras genes. A total of four sets of oligonucleotide primers were used for $A P C$ : Forward, 5'-CAGACTTATTGTGTAGAAGA-3' and reverse, 5'-CTCCTGAAGAAAATTCAACA-3'; forward, 5'-AGGGTT CTAGTTTATCTTCA-3' and reverse, 5'-TCTGCTTGGTGG CATGGTTT-3'; forward, 5'-GGCATTATAAGCCCCAGT GA-3' and reverse, 5'-AAATGGCTCATCGAGGCTCA-3'; forward, 5'-ACTCCAGATGGATTTTCTTG-3' and reverse, 5'-GGCTGGCTTTTTTGCTTTAC-3'. A total of three sets of oligonucleotide primers were used for $p 53$ : Forward, 5'-TGC CCTGACTTTCAACTCTG-3' and reverse: 5'-AGTTGCAAA CCAGACCTCAGG-3'; forward, 5'-CCTGTGTTATCTCCT AGGTTG-3' and reverse, 5'-TCTCCTCCACCGCTTCTT GT-3'; forward, 5'-AAGGCGCACTGGCCTCATCTT-3' and reverse, 5'-GAATCTGAGGCATAACTGCAC-3'. One set of oligonucleotide primers was used for $k$-ras: Forward, 5'-AGG CCTGCTGAAAATGACTGAA-3' and reverse, 5'-AAAGAA TGGTCCTGCACCAG-3'.

Ingenuity Pathways Analysis (IPA). The Ingenuity Pathways Analysis (IPA) platform was used (http://www.ingenuity.com/) to investigate associations between RRM2, p53R2 (RRM2B), KRAS, and miR-211. The platform can reveal molecular interactions according to records contained in its Ingenuity Knowledge Base. The Path Explore tool in the platform was used to identify interactions between the molecules. In total, 13 interacting proteins were identified, including 4 transcription regulators, 3 enzymes, 1 transporter, and 5 proteins with other functions. Among the proteins, BCL2, an apoptosis regulator, serves a central role by interacting with RRM2, KRAS, and miR-211.

Statistical analysis. All data were analyzed using the Statistical Package for the Social Sciences, software (version 13.0; SPSS, Inc., Chicago, IL, USA). A chi-square test ( $\chi^{2}$ test) was used to compare the association of $p 53 R 2$ and $R R M 2$ gene expression with clinical parameters in CRC. A total of two independent tests and $\mathrm{k}$-independent nonparametric tests were used to compare the expression level of $m i R-211$ in the presence of different clinical parameters in CRC. A probability value of $\mathrm{P}<0.05$ was considered statistically significant. Kaplan-Meier survival curves were constructed for overall survival (OS) and disease-free survival (DFS), and the log-rank test was used to evaluate the differences in survival curves of patients with and without $p 53 R 2$ and $R R M 2$ expression. In the present study, survival was defined as the time from the date of the surgical intervention until 31st July 2016.

\section{Results}

RRM2/p53R2 expression is associated with tumoral metastasis in $C R C$. The p53R2 gene was expressed in 93 of $192(48.4 \%)$ patients, and hRRM2 was expressed in 96 of $192(50.0 \%)$ patients. Both proteins were expressed in CRC
Table II. Association between $p 53 R 2$ and $R R M 2$ expression and $A P C$, p53, and $k$-ras gene mutations in patients with colorectal cancer.

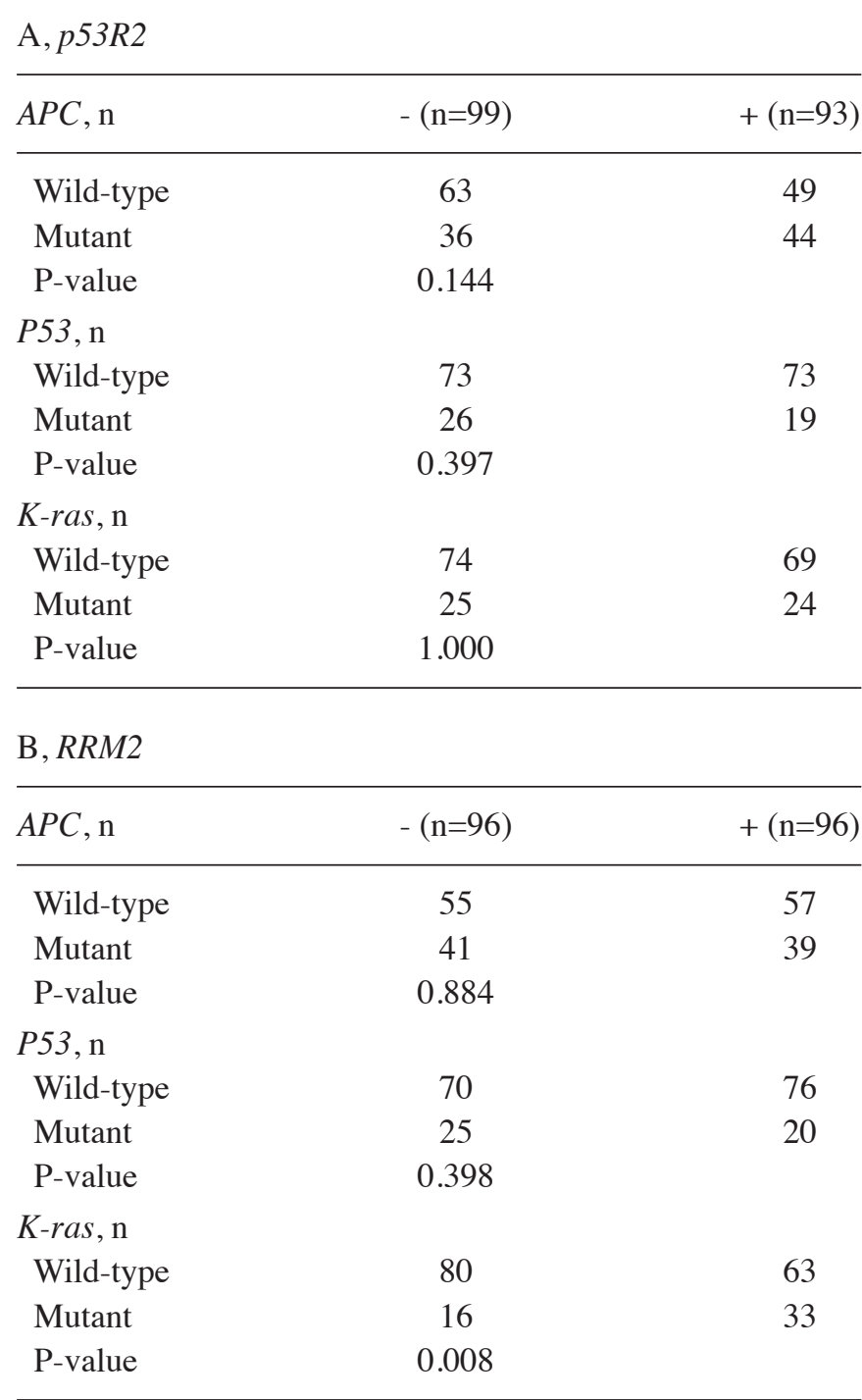

APC, adenomatous polyposis coli; RRM2, ribonucleotide reductase M2; p53R2, ribonucleotide reductase regulatory TP53 inducible subunit M2B.

tumor cells (Fig. 1). As shown in Table I, the expression level of $p 53 R 2$ was significantly lower in patients with distant metastasis and late-stage CRC compared with patients with no metastasis and early-stage $\mathrm{CRC}$ ( $\mathrm{M}$ factor, distant metastasis, $\mathrm{P}=0.002$; stage, $\mathrm{P}=0.008$; Table I). No additional associations were identified between $p 53 R 2$ expression and other clinical parameters (Table I). In addition, RRM2 expression was significantly higher in patients with lymph node metastasis and late-stage CRC compared with patients with no metastasis and early-stage CRC (N factor, lymph node metastasis, $\mathrm{P}=0.001$; stage, $\mathrm{P}=0.001)$. No additional associations were detected between RRM2 and other clinical parameters (Table I).

Effect of RRM2 and p53R2 expression on OS and DFS in $C R C$. We hypothesized that the expression levels of $p 53 R 2$ 
A

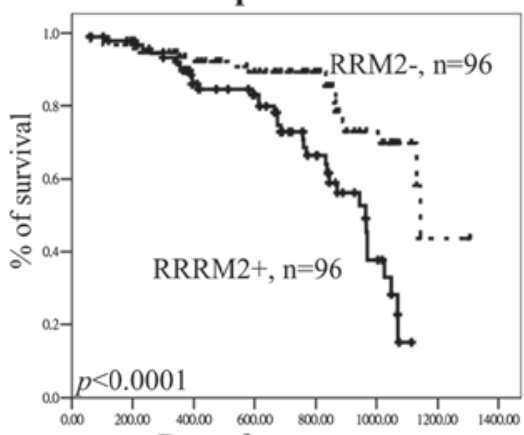

Days after surgery

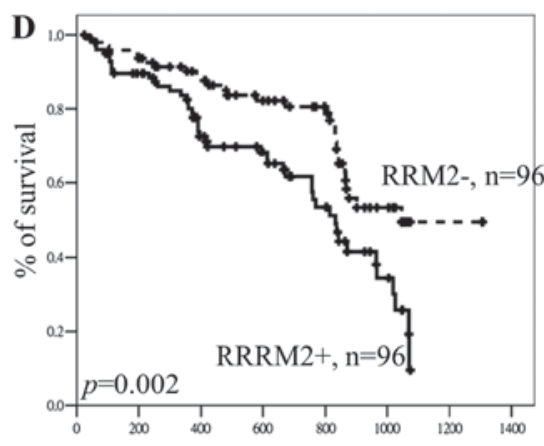

Days after surgery
B Patients with k-ras-wild-type

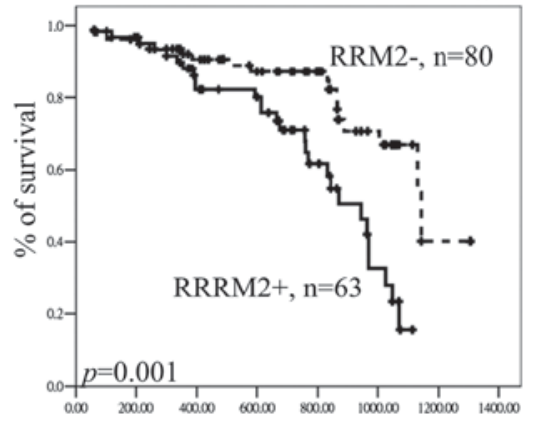

Days after surgery

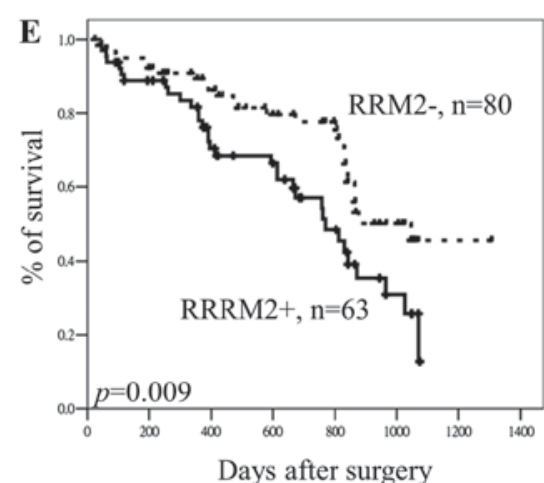

C Patients with k-ras mutations

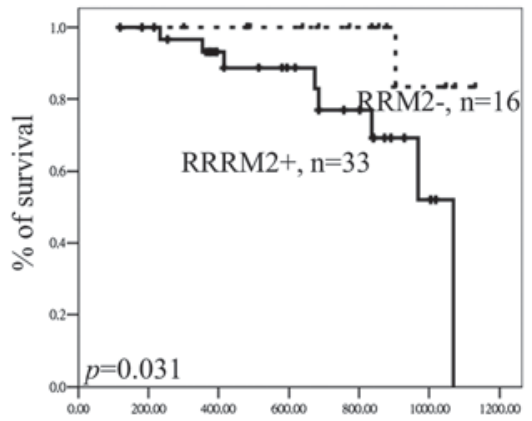

Days after surgery

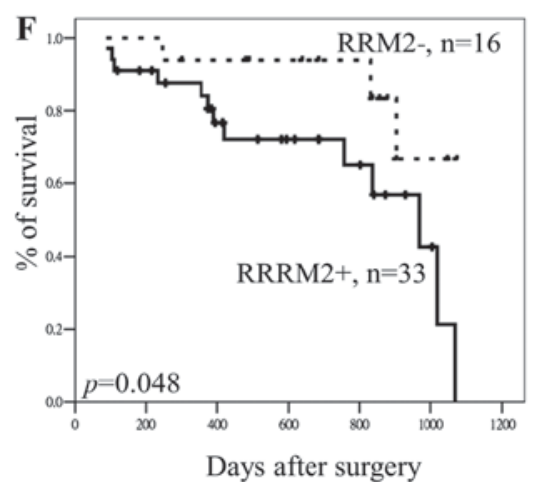

Figure 3. Kaplan-Meier analysis of the effect of $R R M 2$ on the overall survival curves of (A) all patients, and patients with (B) wild-type $k$-ras gene and (C) mutant $k$-ras gene. The effect of $R R M 2$ on the disease-free survival curves of (D) all patients, and patients with (E) wild-type $k$-ras gene and (F) mutant k-ras gene. RRM2, ribonucleotide reductase regulatory subunit M2.

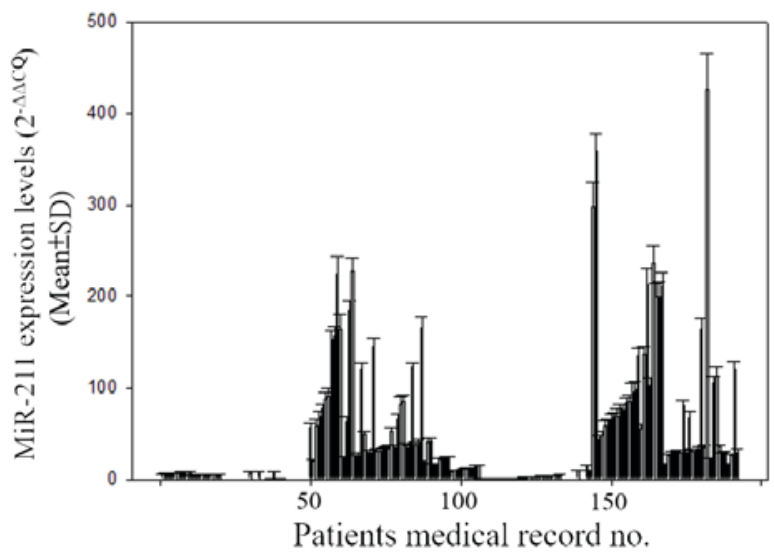

Figure 4. Expression levels of $m i R-211$ in tumor tissues of patients with colorectal cancer as detected by a TaqMan-based miRNA assay and normalized relative to $U 6 B$ using the $2^{-\Delta \Delta C q}$ method. miR, miRNA; SD, standard deviation.

and $R R M 2$ would contribute to tumoral progression and metastasis in CRC and that the expression of $p 53 R 2$ and $R R M 2$ would be associated with OS and DFS in CRC. As indicated by the results of the Kaplan-Meier analysis, $p 53 R 2$ protein expression levels exhibited no association with OS or DFS in $\mathrm{CRC}$ (OS, $\mathrm{P}=0.488$; DFS, $\mathrm{P}=0.915$ for; Fig. 2). However, the results of the Kaplan-Meier analysis demonstrated that $R R M 2$ protein expression was associated with OS and DFS in patients with $\mathrm{CRC}$ (OS, $\mathrm{P}<0.0001$; DFS, $\mathrm{P}=0.002$; Fig. 2). Patients with low RRM2 expression had longer OS and DFS compared patients with high RRM2 expression. Therefore, it is suggested that $R R M 2$ expression has potential to be a prognostic and tumoral recurrence biomarker in patients with CRC.

RRM2 expression is associated with the $k$-ras gene mutation but not with p53/APC gene mutations in patients with CRC. The associations between $p 53 R 2$ and $R R M 2$ expression and gene mutations ( $A P C$, p53 and $k$-ras) in patients with CRC were further analyzed. As indicated in Table II, the expression of p53R2 and RRM2 was not associated with APC or P53 gene mutations in tumors of patients with CRC. A positive association was observed between $R R M 2$ protein expression and the $k$-ras gene mutation. However, there was no association between $p 53 R 2$ expression and the k-ras mutation. In addition, the expression of RRM2 was higher in patients with the $k$-ras gene mutation compared with patients with wild-type $k$-ras $(\mathrm{P}=0.008$; Table II).

Effect of RRM2 expression on OS and DFS of patients with $C R C$ according to $k$-ras status. The results indicated that $R R M 2$ expression was associated with the $k$-ras gene mutation. Therefore, it was hypothesized that the effects of $R R M 2$ expression on OS or DFS in CRC would differ among patients, depending on the presence or absence of $k$-ras mutations. The results of the Kaplan-Meier analysis indicated that $R R M 2$ expression was associated with clinical outcomes in patients with wild-type $k$-ras $(\mathrm{P}=0.001)$ and those with $k$-ras gene mutations $(\mathrm{P}=0.031)$ (all patients, $\mathrm{P}<0.0001$; Fig. $3 \mathrm{~A}-\mathrm{C})$. The association between RRM2 expression and DFS in patients with and without $k$-ras mutations was also analyzed. The 
results revealed that $h R R M 2$ expression was associated with overall DFS in patients with wild-type $k$-ras $(\mathrm{P}=0.009)$ and in those with the $k$-ras gene mutation $(\mathrm{P}=0.048)$ (all patients, $\mathrm{P}=0.002$; Fig. 3D-F). Therefore, it is suggested that $R R M 2$ is not associated with the k-ras gene status but that RRM2 expression may have potential as a prognostic and recurrence marker in patients with CRC.

miR-211 expression negatively regulates RRM2 expression in patients with CRC and k-ras gene mutations. The association of $m i R-211$ with $R R M 2$ expression in tumor tissue samples of patients with CRC was analyzed. The levels of $m i R-211$ expression in tumor tissue samples from patients with CRC are illustrated in Fig. 4. As indicated in Table III, the level of $m i R-211$ was significantly negatively associated with $R R M 2$ protein expression in patients with $\mathrm{CRC}$ and $k$-ras gene mutation $(\mathrm{P}<0.0001)$ but not in patients with $\mathrm{CRC}$ and wild-type $k$-ras gene $(\mathrm{P}=0.634)$. In addition, $m i R-211$ expression was negatively associated with lymph node metastasis, distant metastasis, and cancer stage (all $\mathrm{P}<0.0001$; Table III). Patients with lymph node metastasis, distant metastasis, and late-stage disease had lower miR-211 expression compared with those with early-stage disease and without metastasis (Table III).

Effect of miR-211 expression on OS and DFS in CRC. It was hypothesized that $m i R-211$ expression would be associated with clinical outcomes in patients with CRC, depending on the $k$-ras gene status of the patient. As indicated by the results of the Kaplan-Meier analysis, there was no association between OS and $m i R-211$ expression in overall patients $(\mathrm{P}=0.488$; Fig. 5A) and patients with the wild-type $k$-ras gene $(\mathrm{P}=0.400$; Fig. 5B), but had effects in patients with k-ras gene mutations ( $\mathrm{P}=0.003$, Fig. $5 \mathrm{C})$. In addition, there was no association between $m i R-211$ and DFS in all patients $(\mathrm{P}=0.255$; Fig. 5D) and patients with the wild-type $k$-ras gene $(\mathrm{P}=0.744$; Fig. 5E). However, $m i R-211$ expression had effects on OS and DFS in patients with CRC and $k$-ras gene mutations (Fig. 5C and F), patients with high miR-211 expression having longer OS and DFS compared with patients with low $m i R-211$ expression (OS, $\mathrm{P}=0.003$; Fig. 5C; DFS, $\mathrm{P}=0.004$; Fig. 5F).

The effects of miR-211 and RRM2 expression on OS and DFS were analyzed using the Kaplan-Meier method is presented in Fig. 6. The results indicated that patients with CRC and high $R R M 2 /$ low $m i R-211$ expression and high $R R M 2 /$ high $m i R-211$ expression had significantly poorer $\mathrm{OS}(\mathrm{P}<0.0001$; Fig. 6A) and DFS ( $\mathrm{P}=0.015$; Fig. 6B) compared with those with low $R R M 2 /$ high $m i R-211$ expression and low $R R M 2 /$ low $m i R-211$ expression. A shown by the results of the Cox regression analysis, patients with late-stage disease and high RRM2 expression had a higher hazard ratio compared with patients with early-stage disease and low RRM2 expression (Table IV). $m i R-211$ expression and the presence of the $k$-ras mutation showed no significant different with overall survival of patients with CRC. These observations demonstrated that the expression of $R R M 2$ in tumor tissues rather than the expression of $m i R-211$ could be used as an independent biomarker to predict OS in CRC (Table IV). It is suggested that a combination of $m i R-211$ and $R R M 2$ expression could be used as a prognostic
Table III. Association of $m i R-211$ expression levels and clinical parameters in tumor tissues of patients with colorectal cancer.

\begin{tabular}{|c|c|c|}
\hline \multirow[b]{2}{*}{ Parameters } & \multicolumn{2}{|c|}{$m i R-211$ expression } \\
\hline & $($ Mean \pm SD $)$ & $\mathrm{P}$-value \\
\hline \multicolumn{3}{|l|}{ Age, years } \\
\hline$\leq 65$ & $54.18 \pm 68.41$ & 0.501 \\
\hline$>65$ & $48.23 \pm 71.53$ & \\
\hline \multicolumn{3}{|l|}{ Sex } \\
\hline Female & $53.63 \pm 77.48$ & 0.769 \\
\hline Male & $48.94 \pm 62.76$ & \\
\hline \multicolumn{3}{|l|}{$\mathrm{T}$ factor } \\
\hline 1 & $52.89 \pm 65.55$ & 0.055 \\
\hline 2 & $84.07 \pm 93.65$ & \\
\hline 3 & $44.29 \pm 62.90$ & \\
\hline 4 & $47.29 \pm 66.46$ & \\
\hline \multicolumn{3}{|l|}{$\mathrm{N}$ factor } \\
\hline 0 & $70.58 \pm 77.04$ & $<0.0001$ \\
\hline $1+2$ & $36.34 \pm 60.20$ & \\
\hline \multicolumn{3}{|l|}{ M factor } \\
\hline 0 & $58.26 \pm 73.51$ & $<0.0001$ \\
\hline 1 & $16.83 \pm 31.86$ & \\
\hline \multicolumn{3}{|l|}{ Stage } \\
\hline I & $95.22 \pm 102.20$ & $<0.0001$ \\
\hline II & $75.37 \pm 76.91$ & \\
\hline III & $37.55 \pm 53.40$ & \\
\hline IV & $16.33 \pm 31.50$ & \\
\hline
\end{tabular}

$R R M 2$ expression

Overall

$\begin{array}{lrc}- & 56.39 \pm 69.67 & 0.087 \\ + & 45.90 \pm 70.10 & \\ \text { K-ras wild-type } & & \\ - & 53.45 \pm 60.84 & 0.634 \\ + & 52.91 \pm 74.54 & \\ \text { K-ras mutation } & & \\ - & & <0.0001 \\ + & 32.50 \pm 59.50 & \end{array}$

miR, miRNA; RRM2, ribonucleotide reductase M2; SD, standard deviation.

and tumoral recurrence marker only in patients with CRC and the $k$-ras gene mutation.

\section{Discussion}

Previous reports demonstrated that patients with high $R R M 2$ expression had poor prognoses and tumoral recurrence in several types of cancer, including hepatocellular cancer, prostate cancer, pancreatic cancer, CRC and lung cancer (9,22,24-26). In the present study, it was detected that RRM2 expression in tumor tissues of patients with CRC and lymph node metastasis was significantly higher compared with patients without lymph 
$\mathbf{A}$

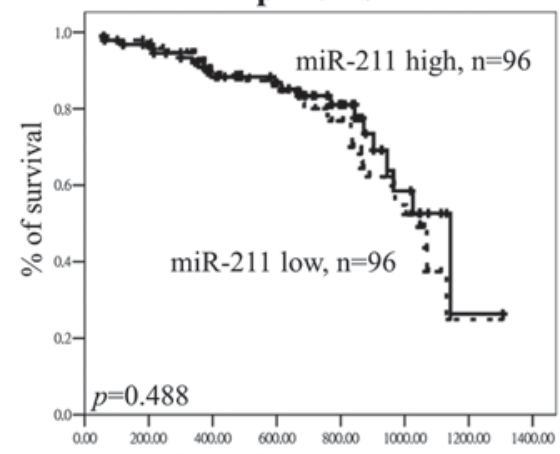

Days after surgery

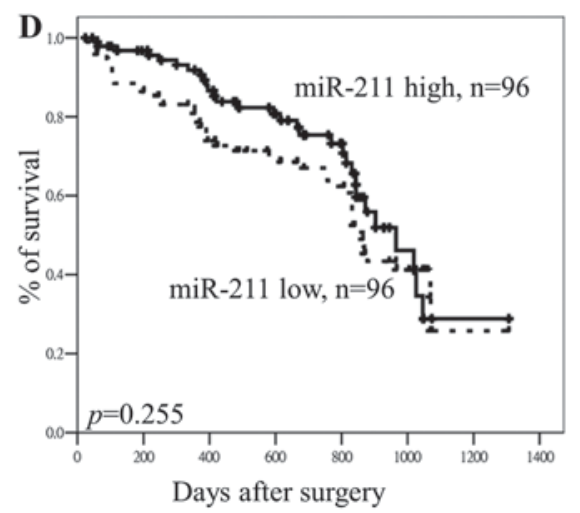

B Patients with k-ras-wild-type

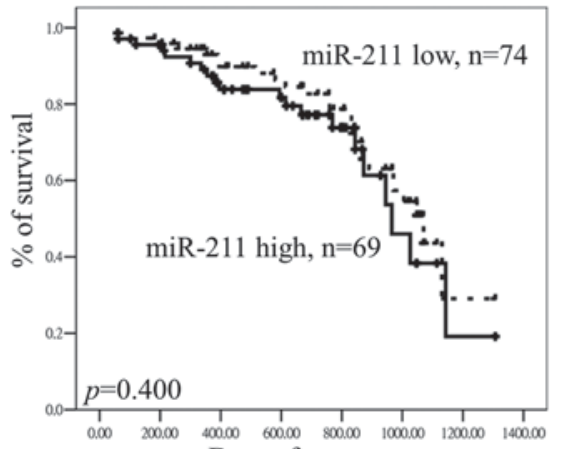

Days after surgery

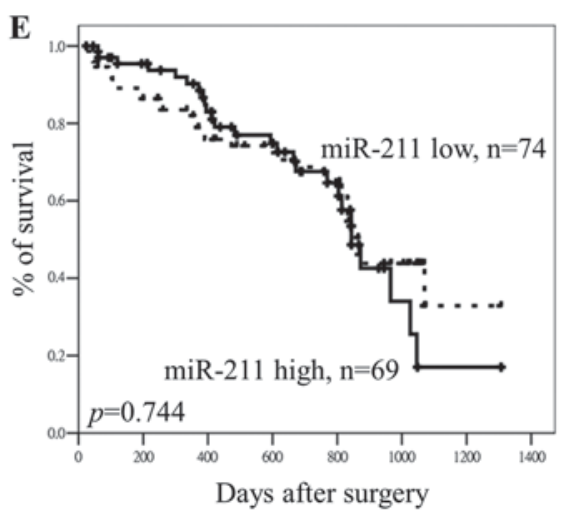

C Patients with k-ras mutations

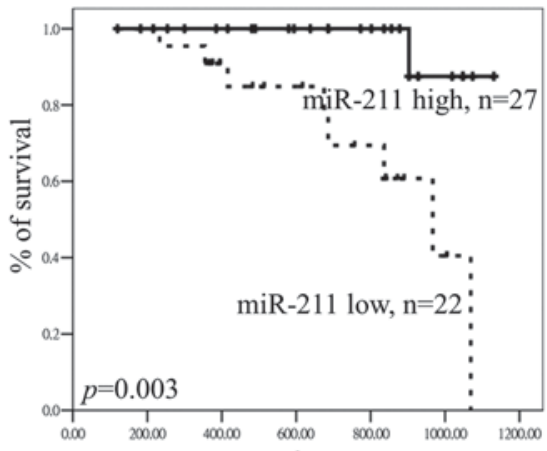

Days after surgery

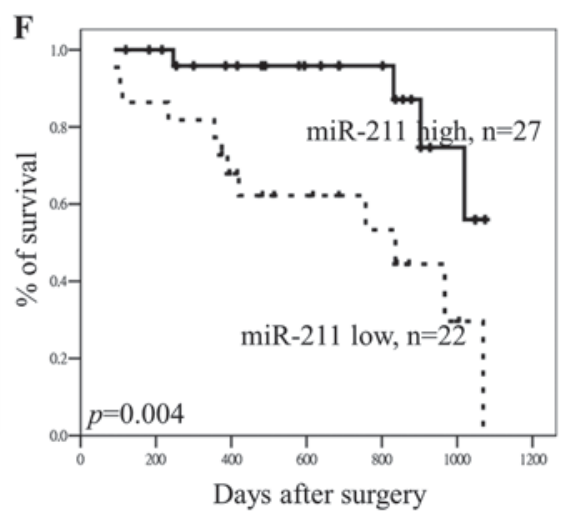

Figure 5. Kaplan-Meier analysis of the effect of miR-211 on overall survival of (A) all patients, and patients with (B) wild-type $k$-ras gene and (C) mutant $k$-ras gene. The effect of $m i R-211$ on the disease-free survival curves of (D) all patients, and patients with (E) wild-type $k$-ras gene and (F) mutant $k$-ras gene.
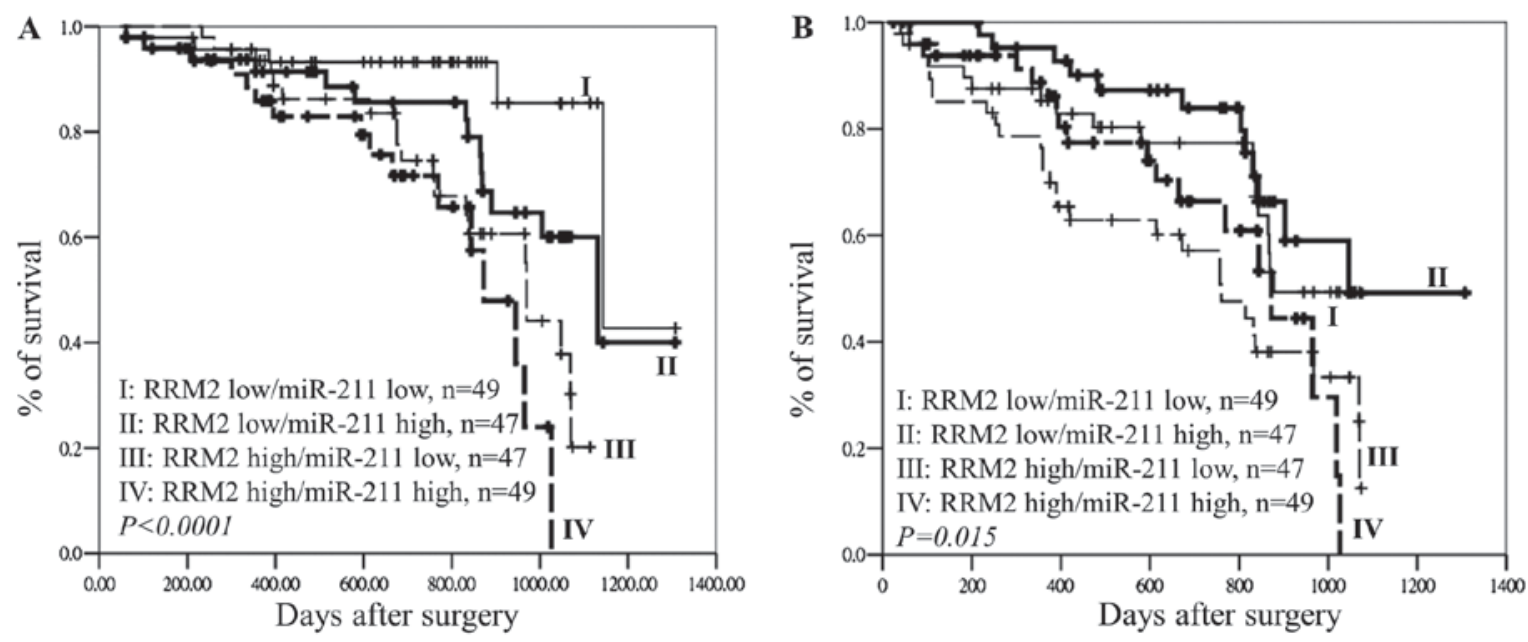

Figure 6. Kaplan-Meier analysis of the effects of a combination of RRM2 and miR-211 expression on the overall survival (A) and disease free survival (B) of patients with colorectal cancer. miR, miRNA; p53R2, ribonucleotide reductase regulatory TP53 inducible subunit M2B; RRM2, ribonucleotide reductase regulatory subunit $\mathrm{M} 2$.

node metastasis (Table I). In addition, patients with high RRM2 expression in tumors had poor DFS (Fig. 2). A previous study by Maftouh et al (27) on SUIT2-007 and SUIT2-028, subclones of a human pancreatic adenocarcinoma cell line (SUIT-2), reported that miR-211 targeted $R R M 2$ and modulated its sensitivity to gemcitabine. In the present study, the expression of $m i R-211$ was negatively associated with $R R M 2$ expression in tumor tissues of patients with CRC and $k$-ras gene mutation (Table III). Tumoral recurrence was lower in patients with $\mathrm{CRC}$ and $k$-ras mutation and high miR-211 expression compared with patients with the $k$-ras mutation and low $m i R-211$ expression. Therefore, it was proposed that the level of $R R M 2$ expression and upstream expression of $m i R-211$ in tumor tissues of patients with CRC may be useful biomarkers to predict tumoral metastasis and tumoral recurrence, particularly in patients with the $k$-ras gene mutation.

A previous study reported that $R R M 2$ cooperated with a variety of oncogenes to promote cell transformation and tumorigenesis in cell model experiments (28). In addition, human and mouse cell models demonstrated that RRM2 played a critical role in enhancing the invasive potential of 
Table IV. Multivariate Cox regression analysis of the combined effects of $R R M 2, m i R-211$, distant metastasis, tumor stage and $k$-ras gene mutation on the overall survival of patients with colorectal cancer.

\begin{tabular}{lccc}
\hline Parameters & HR & $95 \%$ CI & P-value \\
\hline $\begin{array}{l}\text { Tumor stage } \\
\text { Early/late }\end{array}$ & 3.008 & $1.358-6.662$ & 0.007 \\
$\begin{array}{l}\text { Distant metastasis } \\
\text { No/yes }\end{array}$ & 1.233 & $0.669-2.273$ & 0.501 \\
$\begin{array}{l}K \text {-ras mutation } \\
\text { No/yes }\end{array}$ & 0.503 & $0.242-1.043$ & 0.065 \\
$\begin{array}{l}R R M 2 \\
\text { Low/high }\end{array}$ & 2.175 & $1.186-3.987$ & 0.012 \\
$\begin{array}{l}m i R-211 \\
\text { High/low }\end{array}$ & 1.063 & $0.607-1.864$ & 0.830 \\
\hline
\end{tabular}

CI, confidence interval; HR, hazard ratio; miR, miRNA; RRM2, ribonucleotide reductase $\mathrm{M} 2$.

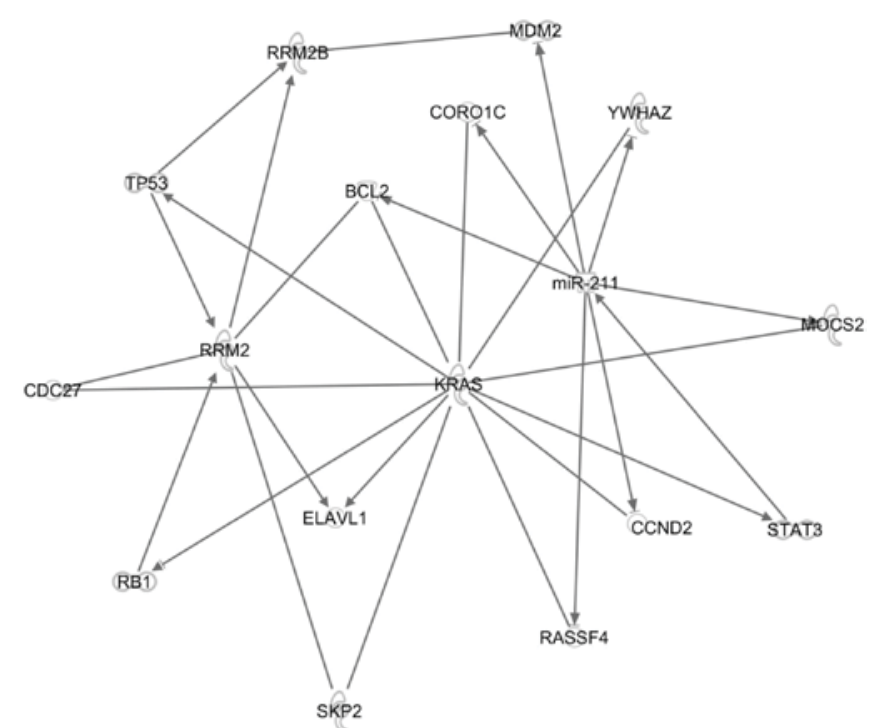

Figure 7. Potential associations between $p 53 R 2, R R M 2, m i R-211, k$-ras and associated target genes as detected using the Ingenuity Pathways Analysis platform. miR, miRNA; p53R2, ribonucleotide reductase regulatory TP53 inducible subunit M2B; RRM2, ribonucleotide reductase regulatory subunit M2.

tumor cells (28-31). In the present study, $R R M 2$ expression was higher in lymph nodes invasion groups compared with the group without invasion (Table I). Therefore, it was suggested that RRM2 expression in patients with CRC may be associated with increased metastasis of tumor cells.

As shown in a previous study, $m i R-211$ modulated gemcitabine activity and inhibited the invasive ability of cancer cells by negatively regulating the expression of $R R M 2$ (27). The downregulation of let-7a and $m i R-211$ was associated with the overexpression of $k$-ras in 9, 10-dimethyl-1,2-benz [a]anthracene-induced mouse skin tumorigenesis (32). In the present study, the expression of $m i R-211$ was negatively associated with $R R M 2$ expression in tumor tissues of patients with CRC and $k$-ras mutation. Patients with low $m i R-211$ expression and high RRM2 expression had poor DFS, particularly those with the $k$-ras mutation. Therefore, it was suggested that the $k$-ras gene mutation may be associated with downregulation of $m i R-211$ and that this results in the overexpression of RRM2 and the induction of CRC tumorigenesis.

A meta-analysis indicated that the $k$-ras mutation was present in 1,364 of 4,687 (29.10\%) patients with CRC (33). This result is similar to the results found in the present study (25.5\%; Table II). Previous studies reported an association between $k$-ras gene mutation and clinicopathological characteristics (34-37). However, the association remains unclear, where some reports demonstrated that the $k$-ras gene mutation appeared to be associated with clinical outcomes, while other studies found no evidence to suggest that it could be used to predict clinical outcomes (34-37). The present study demonstrated that patients with low miR-211 expression had poor DFS, as did patients with the k-ras gene mutation. By contrast, the wild-type $k$-ras gene was not associated with poor DFS. A negative association was detected between $R R M 2$ and $m i R$-211 expression in patients with CRC and $k$-ras gene mutation (Table III). These findings indicate that a combination of $k$-ras gene mutation and $m i R-211$ and $R R M 2$ expression, may be a useful biomarker to monitor tumoral recurrence in CRC. However, $k$-ras alone cannot be used as a biomarker.

In the present study, the IPA platform was used to investigate the associations between RRM2, p53R2, (RRM2B), $k$-ras and $m i R-211$. The platform can reveal molecular interactions between these genes based on data recorded in the Ingenuity Knowledge Base. The Path Explore tool in IPA was used to identify interactions between the molecules (Fig. 7). The following 13 interacting proteins were identified: Transcription regulators $(n=4)$, enzymes $(n=3)$, transporters $(n=1)$ and proteins $(n=5)$ with other functions. One of the proteins identified, $B c l 2$ is an apoptosis regulator, and it plays a central role by interacting with RRM2, k-ras and miR-211. The associations of these 13 target genes (Fig. 7) and the clinical application of these genes need to be examined in future studies.

In conclusion, it was detected that $R R M 2$ and $p 53 R 2$ protein expression was associated with lymph node and distant metastasis in CRC. Additionally, the expression level of RRM2 was regulated by $m i R-211$. The protein expression of $m i R-211$ and $R R M 2$ but not that of $p 53 R 2$ could be used to monitor metastasis, OS, and DFS in CRC, particularly in patients with $\mathrm{CRC}$ and $k$-ras gene mutation. The present authors propose that the activation of the $k$-ras gene may downregulate the expression of mir-211, resulting in RRM2 overexpression and the induction of tumoral recurrence in patients with CRC and $k$-ras gene mutation.

\section{Acknowledgements}

Not applicable.

\section{Funding}

The present study was supported by grants from the Health and Welfare Surcharge of Tobacco Products (grant 
no. MOHW105-TDU-B-212-134001) and the Ministry of Health and Welfare of Taiwan (grant nos. MOHW103-TD-B-111-01 and MOHW103-TDU-B-212-113001).

\section{Availability of data and materials}

The datasets used and/or analyzed during the current study are available from the corresponding author on reasonable request.

\section{Authors' contributions}

YWC designed the study and wrote the paper. YWC, CCC, KTY, CCH and NYH designed the experiments, wrote the paper, and prepared the figures. CCL, CHW, KTY, PLW and $\mathrm{CCH}$ collected the colorectal tumor samples and clinical data. TWK evaluated the immunohistochemistry results. $\mathrm{KCH}$ analyzed the molecular pathway using the Ingenuity Pathways Analysis platform. All the authors gave their approval for the manuscript to be submitted for publication.

\section{Ethics approval and consent to participate}

The acquisition of the samples and their subsequent examination were approved by the Institutional Review Board of Taipei Medical University (Taipei, Taiwan). Informed written consent was obtained from all the patients and/or guardians prior to the use of the resected specimens.

\section{Consent for publication}

All identifying information is removed.

\section{Competing interests}

The authors declare that they have no competing interests.

\section{References}

1. Su SY, Huang JY, Jian ZH, Ho CC, Lung CC and Liaw YP Mortality of colorectal cancer in Taiwan, 1971-2010: Temporal changes and age-period-cohort analysis. Int J Colorectal Dis 27: 1665-1672, 2012.

2. Taiwan Cancer Registry. http://tcr.cph.ntu.edu.tw/main. php?Page $=\mathrm{N} 1$

3. Chiang CJ, Lo WC, Yang YW, You SL, Chen CJ and Lai MS: Incidence and survival of adult cancer patients in Taiwan, 2002-2012. J Formos Med Assoc 115: 1076-1088, 2016.

4. Chen TH, Chang SW, Huang CC, Wang KL, Yeh KT, Liu CN, Lee H, Lin CC and Cheng YW: The prognostic significance of APC gene mutation and miR-21 expression in advanced-stage colorectal cancer. Colorectal Dis 15: 1367-1374. 2013.

5. Fodde R, Smits R and Clevers H: APC, signal transduction and genetic instability in colorectal cancer. Nat Rev Cancer 1: 55-67, 2001.

6. Reichard P: Ribonucleotide reductases: The evolution of allosteric regulation. Arch Biochem Biophy 397: 149-155, 2002

7. Tanaka H, Arakawa H, Yamaguchi T, Shiraishi K, Fukuda S, Matsui K, Takei Y and Nakamura Y: Ribonucleotide reductase gene involved in a p53-dependent cell-cycle checkpoint for DNA damage. Nature 404: 42-49, 2000.

8. Fan H, Villegas $\mathrm{C}$ and Wright JA: Ribonucleotide reductase $\mathrm{R} 2$ component is a novel malignancy determinant that cooperates with activated oncogenes to determine transformation and malignant potential. Proc Natl Acad Sci USA 93: 14036-14040, 1996.
9. Liu X, Zhou B, Xue L, Shih J, Tye K, Lin W, Qi C, Chu P, Un F, Wen W and Yen Y: Metastasis-suppressing potential of ribonucleotide reductase small subunit p53R2 in human cancer cells. Clin Cancer Res 12: 6337-6344, 2006.

10. Liu X, Zhang H, Lai L, Wang X, Loera S, Xue L, He H, Zhang K, Hu S, Huang Y, et al: Ribouncleotide reductase small subunit M2 serves as a prognostic biomarker and predicts poor survival of colorectal cancers. Clin Sci (Lond) 124: 567-578, 2013.

11. Cerqueira NM, Pereira S, Fernandes PA and Ramos MJ: Overview of ribonucleotide reductase inhibitors: An appealing target in anti-tumour therapy. Curr Med Chem 12: 1283-1294, 2005.

12. Slack FJ and Weidhaas JB: MicroRNA in cancer prognosis. N Engl J Med 359: 2720-2722, 2008.

13. Ke TW, Hsu HL, Wu YH, Chen WT, Cheng YW and Cheng CW: MicroRNA-224 suppresses colorectal cancer cell migration by targeting Cdc42. Dis Markers 2014: 617150, 2014.

14. Liu TP, Huang CC, Yeh KT, Ke TW, Wei PL and Cheng YW: Down-regulation of let-7a-5p predicts lymph node metastasis and prognosis impact on chemotherapy of colorectal cancer. Surg Oncol 25: 429-434, 2016.

15. Chen X and Qin Z: Post-transcriptional regulation by microRNA-21 and let-7a microRNA in paediatric cholesteatoma. J Int Med Res 39: 2110-2118, 2011.

16. Pfeffer SR, Yang CH and Pfeffer LM: The role of miR-21 in cancer. Drug Dev Res 76: 270-277, 2015.

17. Zhang $\mathrm{F}$ and Cheong JK: The renewed battle against RAS-mutant cancers. Cell Mol Life Sci 73: 1845-1858, 2016.

18. Rui YY, Zhang D, Zhou ZG, Wang C, Yang L, Yu YY and Chen HN: Can K-ras Gene mutation be utilized as prognostic biomarker for colorectal cancer patients receiving chemotherapy? A meta-analysis and systematic review. PLoS One 8: e77901, 2013.

19. Normanno N, Tejpar S, Morgillo F, De Luca A, Van Cutsem E and Ciardiello F: Implications for KRAS status and EGFR-targeted therapies in metastatic CRC. Nat Rev Clin Oncol 6: 519-527, 2009.

20. Yoshida Y, Tsunoda T, Doi K, Tanaka Y, Fujimoto T, Machida T, Ota T, Koyanagi M, Takashima Y, Sasazuki T, et al: KRAS-mediated up-regulation of RRM2 expression is essential for the proliferation of colorectal cancer cell lines. Anticancer Res 31: 2535-2539, 2011.

21. Livak KJ and Schmittgen TD: Analysis of relative gene expression data using real-time quantitative PCR and the 2(-Delta Delta C(T)) method. Methods 25: 402-408, 2001.

22. Hsu NY, Wu JY, Liu X, Yen Y, Chen CY, Chou MC, Lin CH, Lee $\mathrm{H}$ and Cheng YW: Expression status of ribonucleotide reductase small subunits hRRM2/p53R2 as prognostic biomarkers in stage $\mathrm{i}$ and ii non-small cell lung cancer. Anticancer Res 31: 3475-3481, 2011.

23. Chen IC, Lee KH, Hsu YH, Wang WR, Chen CM and Cheng YW: Expression pattern and clinicopathological relevance of the indoleamine 2,3-dioxygenase 1/tryptophan 2,3-dioxygenase protein in colorectal cancer. Dis Markers 2016: 8169724, 2016.

24. Huang Y, Liu X, Wang YH, Yeh SD, Chen CL, Nelson RA, Chu P, Wilson $\mathrm{T}$ and Yen Y: The prognostic value of ribonucleotide reductase small subunit M2 in predicting recurrence for prostate cancers. Urol Oncol 32: 51.e9-e19, 2014.

25. Wei CH, Gorgan TR, Elashoff DA, Hines OJ, Farrell JJ and Donahue TR: A meta-analysis of gemcitabine biomarkers in patients with pancreaticobiliary cancers. Pancreas 42: 1303-1310, 2013.

26. Wang L, Huang J and Jiang M: RRM2 computational phosphoprotein network construction and analysis between no-tumor hepatitis/cirrhotic liver tissues and human hepatocellular carcinoma (HCC). Cell Physiol Biochem 26: 303-310, 2010.

27. Maftouh M, Avan A, Funel N, Frampton AE, Fiuji H, Pelliccioni S, Castellano L, Galla V, Peters GJ and Giovannetti E: miR-211 modulates gemcitabine activity through downregulation of ribonucleotide reductase and inhibits the invasive behavior of pancreatic cancer cells. Nucleosides Nucleotides Nucleic Acids 33: 384-393, 2014.

28. Zhong Z, Cao Y, Yang S and Zhang S: Overexpression of RRM2 in gastric cancer cell promotes their invasiveness via AKT/NF- $\kappa B$ signaling pathway. Pharmazie 71: 280-284, 2016.

29. Fang Z, Gong C, Liu H, Zhang X, Mei L, Song M, Qiu L, Luo S, Zhu Z, Zhang R, et al: E2F1 promote the aggressiveness of human colorectal cancer by activating the ribonucleotide reductase small subunit M2. Biochem Biophys Res Commun 464: 407-415, 2015. 
30. Zhou BS, Tsai P, Ker R, Tsai J, Ho R, Yu J, Shih J and Yen Y: Overexpression of transfected human ribonucleotide reductase M2 subunit in human cancer cells enhances their invasive potential. Clin Exp Metastasis 16: 43-49, 1998

31. Duxbury MS and Whang EE: RRM2 induces NF-kB-dependent MMP-9 activation and enhances cellular invasiveness. Biochem Biophys Res Commun 354: 190-196, 2007.

32. Tiwari P, Sahay S, Pandey M, Qadri SS and Gupta KP: Preventive effects of butyric acid, nicotinamide, calcium glucarate alone or in combination during the 7, 12-dimethylbenz anthracene induced mouse skin tumorigenesis via modulation of K-Ras-PI3K-AKTpathway and associated micro RNAs. Biochimie 121: 112-122, 2016

33. Ren J, Li G, Ge J, Li X and Zhao Y: Is K-ras gene mutation a prognostic factor for colorectal cancer: A systematic review and meta-analysis. Dis Colon Rectum 55: 913-923, 2012.
34. Bazan V,Migliavacca M,Zanna I,TubioloC,Grassi N,Latteri MA, La Farina M, Albanese I, Dardanoni G, Salerno S, et al: Specific codon $13 \mathrm{~K}$-ras mutations are predictive of clinical outcome in colorectal cancer patients, whereas codon $12 \mathrm{~K}$-ras mutations are associated with mucinous histotype. Ann Oncol 13: 1438-1446, 2002.

35. Conlin A, Smith G, Carey FA, Wolf CR and Steele RJ: The prognostic significance of K-ras, p53 and APC mutations in colorectal carcinoma. Gut 54: 1283-1286, 2005.

36. Pricolo VE, Finkelstein SD, Wu TT, Keller G, Bakker A Swalsky PA and Bland KI: Prognostic value of TP53 and K-ras-2 mutational analysis in stage III carcinoma of the colon. Am J Surg 171: 41-46, 1996

37. Andersen SN, Lovig T, Breivik J, Lund E, Gaudernack G, Meling GI and Rognum TO: K-ras mutations and prognosis in large-bowel carcinomas. Scand J Gastroenterol 32: 62-69, 1997. 